\title{
IGF1 Positive
}

National Cancer Institute

\section{Source}

National Cancer Institute. IGF1 Positive. NCI Thesaurus. Code C138950.

Indicates that IGF1 expression has been detected in a sample. 